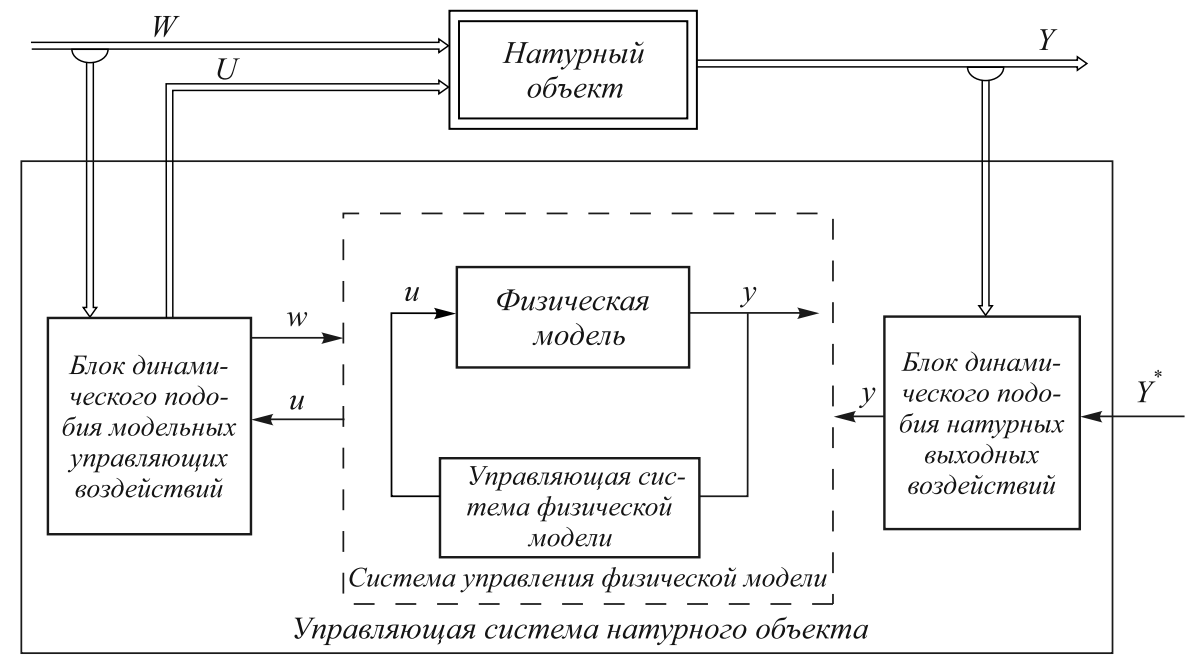

Система управления с физической моделью

$$
\Delta \tau(i)=\left\{\begin{array}{c}
k_{1}\left\{T^{\mathrm{p}}(i)-T^{\mathrm{M}}(i)\right\} \\
k_{2}\left\{T^{\mathrm{p}}(i)-T^{\mathrm{M}}(i)\right\}
\end{array}\right\} \begin{aligned}
& \text { при }\{\cdot\} \leq 0 ; \\
& \text { при }\{\cdot\}>0,
\end{aligned}
$$

где $\Delta \tau(i)$ - время дополнительного нагрева или охлаждения модельного изделия на $i$-ом такте управления; $T^{\mathrm{p}}$ - температура натурного изделия, переведенная в масштаб модельного; $T^{\text {м }}$ - температура модельного изделия; $k_{1}, k_{2}$ - пересчетные коэффициенты.

После выравнивания температур натурного и модельного изделий рассчитывали новую траекторию на- грева, включающую величину и длительность нагрева с использованием физической модели. Затем полученная траектория пересчитывалась с помощью коэффициентов в траекторию нагрева натурных изделий.

Таким образом, использование физических моделей и блоков обеспечения динамического подобия в системе управления структурой и свойствами сталей при термоциклической обработке позволяет повысить эффективность управления в условиях неопределенности.

(С) 2012 г. С.Н. Староваикая, Л.П. Мышляев Поступила 22 октября 2012 г.

УДК 621.745.34:66.041.88

\title{
А.В. Феоктистов
}

Сибирский государственный индустриальный университет

\section{ОПЫТ ЭКСПЛУАТАЦИИ ВАГРАНОЧНОГО РЕКУПЕРАТОРА КОНСТРУКЦИИ «ТРУБА В ТРУБЕ»}

В вагранках с горячим дутьем часто используются рекуператоры из жаропрочной стали. При этом в зависимости от конструкции рекуператора, от состава и крупности шихтовых материалов температура горячего дутья находится в пределах от 400 до $620^{\circ} \mathrm{C}$. Однако такие рекуператоры в производственных условиях показали себя не надежными в работе из-за большой длины воздушного тракта, подсоса воздуха через несплошности и частых взрывов смеси газов, засорения и прогара жаростойких труб. Из сказанного следует, что необходимы новые конструктивные решения по разработке

* Работа выполнена по заказу Министерства образования и науки РФ (№ 7.3909.2011). рекуператоров, способных осуществлять подогрев дутья свыше $400{ }^{\circ} \mathrm{C}$ и работать в условиях длительной кампании.

С целью поиска оптимальной конструкции рекуператора на кафедре литейного производства СибГИУ были разработаны различные конструкции рекуператоров типа «труба в трубе» и методика расчета их технологических параметров, включающая расчет состава колошниковых газов; расчет температуры воздуха и дымовых газов на выходе из рекуператора; расчет коэффициентов теплообмена и теплопередачи на дымовой стороне; расчет температуры подогрева воздуха для противотока; расчет температуры подогрева воздуха для прямотока; расчет количества воздуха на дожигание оксида углеро- 
да в колошниковых газах. В процессе расчета основных параметров рекуператора по разработанной методике возможно варьировать его геометрические размеры и направление движения воздуха в нем.

Оптимальная конструкция рекуператора, установленного на вагранке диам. 1250 мм ЗАО «Изолит» и показавшая наилучшие результаты в процессе эксплуатации, представлена на рисунке и защищена патентами [1-4]. Такая конструкция позволяет подогревать дутье до $450{ }^{\circ} \mathrm{C}$. Срок службы рекуператора составляет уже 2 года и пока не наблюдается каких-либо нарушений в его работе. Так как в вагранке проплавляется доменный шлак, в состав которого входят $38-40 \% \mathrm{SiO}_{2}$, $18-20 \% \mathrm{Al}_{2} \mathrm{O}_{3}$, оксиды Са и $\mathrm{Mg}$, то поверхность труб рекуператора при нагреве в процессе работы подверглась алитированию и силицированию, т.е. покрылась пленкой оксидов алюминия и кремния, которые диффузионно проникли и насытили поверхность стальных труб. Поэтому окисления стальной поверхности и, тем более, прогара стенок труб не происходит

Особенности расчета ваграночного рекуператора состоят в том, что его высота уже ограничена конструктивными особенностями вагранки, т.е. высотой верхней шахты от верха загрузочного окна до выхода газов в искрогаситель. Диаметры двух цилиндров рекуператора «труба в трубе» также определяются диаметром верхней шахты вагранки. Для расчета необходимо экспериментально определить средний состав колошниковых газов вагранки и их температуру. При устройстве такого рекуператора ваграночный процесс надо вести так, чтобы температура отходящих газов не опускалась ниже пределов воспламенения $630-650{ }^{\circ} \mathrm{C}$.

В результате расчетов, лабораторной и промышленной практики выявлено, что без установки дополнительной горелки ниже загрузочного окна полезную высоту вагранки следует держать на уровне 4-4,5 м от первого ряда фурм. Только в этом случае отходящие колошниковые газы будут иметь необходимую температуру. На высоких вагранках большого внутреннего диаметра и большей полезной высотой воспламенение монооксида углерода следует производить с помощью дополнительной горелки, работающей на природном газе. Поэтому для расчета должно задаваться начальное содержание монооксида углерода в составе колошниковых газов и затем вычисляться количество воздуха, которое необходимо для дожигания этого количества оксида углерода.

Для методически верного расчета, являющегося основой реального проектирования, задавались следующие параметры: коэффициент избытка воздуха; температура колошниковых газов; температура газов на выходе из рекуператора; температура дутья; количество дутья; температура воздуха на дожигании монооксида углерода; тепловой эффект реакции $\mathrm{CO}+0,5 \mathrm{O}_{2}=\mathrm{CO}_{2}+Q$, где $Q=282583$ кДж/кмоль; степень черноты материала стенки рекуперато-

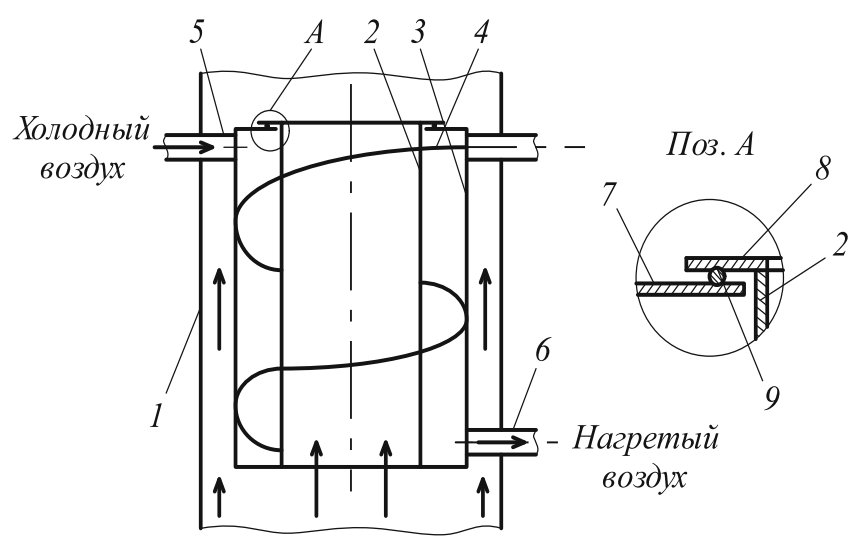

Конструкция рекуператора:

1 - шахта вагранки; 2 - внутренний цилиндр; 3 - внешний цилиндр; 4 - винтовая насадка; 5 - патрубок подвода холодного воздуха; 6 - патрубок отвода нагретого воздуха; 7 - нижнее кольцо; 8 - верхнее кольцо; 9 - шнур из углестекловолокна

ра - 0,98; средние теплоемкости газов и воздуха 1,50 и 1,34 кДж/( $\left.\mathrm{M}^{3 .} \mathrm{C}\right)$ в рекуператоре. Расчет данного типа рекуператора проводился только численным методом с применением итерационной процедуры.

Для оптимизации методики расчета технологических параметров рекуператора конструкции «труба в трубе» была разработана программа в среде Borland Delphi, позволяющая моделировать протекающие процессы теплообмена в рекуператоре [5]. В результате проведенных расчетов были получены значения, которые хорошо подтверждаются практическими данными. Были выработаны технологические решения для проектирования и последующего монтажа рекуператора на вагранках с различной температурой подогрева воздуха в рекуператоре; из расчета был сделан вывод о том, что для рекуператора конструкции «труба в трубе» прямоток оказывается более эффективным, чем противоток.

\section{БИБЛИОГРАФИЧЕСКИЙ СПИСОК}

1. Пат. 89682 РФ, МПК F27B1/00, F23L15/04. Рекуператор вагранки / Пашков В.В., Селянин И.Ф., Феоктистов А.В. и др.; ГОУ ВПО «СибГИУ». № 2009128152/22; заявл. 21.07.09; опубл. 10.12.09.

2. Пат. 89683 РФ, МПК F27B1/00. Рекуператор вагранки / Пашков В.В., Селянин И.Ф., Феоктистов А.В. и др.; ГОУ ВПО «СибГИУ». № 2009128151/22; заявл. 21.07.09; опубл. 10.12.09.

3. Пат. 89684 РФ, МПК F 27 В 1/00. Рекуператор вагранки / Пашков В.В., Селянин И.Ф., Феоктистов А.В. и др.; ГОУ ВПО «СибГИУ». № 2009128149/22; заявл. 21.07.09; опубл. 10.12.09.

4. Пат. 99135 РФ, МПК F28D1/00. Рекуператор вагранки / Селянин И.Ф., Пашков В.В., Куценко А.И., Феоктистов А.В., Бедарев С.А. ; ГОУ ВПО «СибГИУ». № 2010125296/02 ; заявл. 18.06.2010 ; опубл. 10.11.10.

5. Свидетельство № 2011617034 о государственной регистрации программы для ЭВМ "Расчет технологических параметров ваграночного рекуператора конструкции «труба в трубе»" / Селянин И.Ф., Феоктистов А.В., Бедарев С.А., Морин С.В. Заявл. 12.07.11; зарег. 09.09.11. 